\title{
Carbonization, Differential Preservation, and Sampling Biases in Domestication Studies: An Erect Knotweed (Polygonum erectum L.) Case Study
}

\section{Natalie G. Mueller ${ }^{1}$}

\begin{abstract}
Population morphometrics can be employed to explore the process of domestication, but only after accounting for biases introduced by taphonomic processes and sampling. For every cultivated plant, the challenges associated with carbonization, differential preservation, and sampling bias are different, as are the morphological characteristics of interest in domestication studies. This case study establishes correction factors and sampling parameters for assessing morphological indicators of domestication in erect knotweed (Polygonum erectum L.), an annual plant that was cultivated by Indigenous people in Eastern North America for about 2500 years. Documenting the unique domestication syndrome of erect knotweed creates three different sets of taphonomic and sampling problems that need to be addressed through experimentation and modeling: 1) Assess the morphometric effects of carbonization; 2) assess the effects of differential preservation; and 3) assess the effects of sampling error. The results of this study can be used by other analysts to identify domesticated assemblages of erect knotweed. These analyses also have implications for studies of plant domestication from the morphology of archaeological assemblages in general, especially when nominal variables are used to differentiate wild from domesticated populations (for example, the presence/absence of an abscission scar in cereals or the seed coat texture of chenopods).
\end{abstract}

\section{Introduction}

The analyses reported here were undertaken in the course of a study on erect knotweed (Polygonum erectum L.), an annual seed crop that was cultivated by ancient farmers in Eastern North America (ENA)

\footnotetext{
${ }^{1}$ Washington University in St. Louis, Department of Anthropology
} 
from c. 3000-600 BP. Elsewhere, I have argued on the basis of population morphometrics that some assemblages of erect knotweed exhibit a unique domestication syndrome as a result of hundreds of generations of selection in agroecosystems (Mueller 2017a; 2017b; 2017c). It is only possible to make such arguments, which are built on morphological comparisons of crop plants and their wild progenitors, after first exploring the many possible ways that archaeological assemblages may be altered and biased. For every cultivated plant, the challenges associated with carbonization, differential preservation, and sampling bias are different, as are the morphological characteristics of interest in domestication studies (Boardman and Jones 1990; Smith 2014; Wright 2003; 2008; Yarnell 1978). The purposes of this paper are 1) to provide guidelines for the identification of domesticated erect knotweed from its carbonized fruits; and 2) to address sampling and preservation issues common to all domestication studies that rely on the morphology of carbonized remains.

In ENA, an indigenous agricultural system began to develop c. 4000 BP. These early crops include some familiar plants: sunflowers (Helianthus anuus var. macrocarpus (DC.) Cockerell) and native squash varieties, such as acorn and crookneck squashes (Cucurbita pepo L. ssp. ovifera D.S. Decker), are among ENA's earliest domesticates (Crites 1993; Kay 1980). Sumpweed (Iva annua L. and its domesticated subspecies, Iva annua ssp. macrocarpa S.F. Blake) and goosefoot (Chenopodium berlandieri Moq. and its domesticated subspecies, Chenopodium berlandieri ssp. jonesianum Smith and Funk) were also domesticated by c. 3800 BP (Smith and Funk 1985; Smith and Yarnell 2009; Yarnell 1972; 1978). By the Early Woodland period, c. 3,000 BP, three new crops had entered the crop complex. These were maygrass (Phalaris caroliniana Walter), erect knotweed (Polygonum erectum L. and its domesticated subspecies Polygonum erectum ssp. watsoniae N.G. Muell.), and little barley (Hordeum pusillum Nutt.) (Asch and Asch 1978; 1985; Fritz 1986; 1993; Mueller 2016c; Simon and Parker 2006). By the time of European colonization, several of these locally domesticated crops had apparently fallen out of use and were thus lost to history (Smith 1992; 2006). Collectively, the native seed crops of ENA are referred to as the Eastern Agricultural Complex (EAC). EAC crops are commonly recovered from storage pits, hearths, 
and middens at archaeological sites spanning parts of modern day Arkansas, Illinois, Indiana, Iowa, Kentucky, Missouri, Ohio, and Tennessee (the “core area," Fritz 1993). Erect knotweed has been recovered from sites spanning the core area. It seems to have entered the crop complex in western Appalachia c. 3,000 BP and was cultivated at least until c. 600 BP. Domesticated assemblages have been recovered from the Middle Woodland Walker Noe site, Kentucky (c. 2000 BP), and from Mississippian sites in Illinois, Missouri, and Arkansas (1000-600 BP) (Mueller 2017c).

Erect knotweed produces achenes: one-seeded fruits with hard pericarps (fruit coats). Each plant produces two distinctly different types of achenes, a phenomenon known as fruit dimorphism (Figure 1). Throughout the growing season, erect knotweed produces tubercled achenes, which have thicker pericarps and do not germinate readily (Mueller 2017d). Beginning in mid-September, it begins to produce smooth achenes, which have thinner pericarps and almost always germinate the spring after they are produced. This phenomenon is called germination heteromorphism, and is a form of evolutionary bet-hedging (Slatkin 1974; Silvertown 1984; Childs et al. 2010). The tubercled morphs persist in the seed bank, allowing populations to survive adverse growing seasons (Mueller 2017d). Domesticated erect knotweed (Polygonum erectum ssp. watsoniae N.G. Muell.) differs from its wild progenitor in that 1) its achenes are larger and differently shaped and; 2) harvests from domesticated plants contain very few or no tubercled morphs (Mueller 2017a; 2017b). Documenting this unique domestication syndrome creates three different sets of taphonomic and sampling problems that need to be addressed through experimentation and modeling.

1) Assess the morphometric effects of carbonization. Carbonization preserves plant parts which would otherwise be subject to decay by converting starch, protein, lignin and other constituents of plant tissues into inert compounds when plant parts are exposed to heat in an anoxic or near anoxic environment (Braadbart et al. 2004). Unfortunately, the process also distorts the original shape and size of the seed. In order to compare carbonized assemblages to modern reference collections and desiccated archaeological assemblages, correction factors must be applied. For 
erect knotweed, only preliminary correction factors for achene length and width existed prior to this study (Asch and Asch 1985:144). Changes in shape had never been investigated.

2) Assess the effects of differential preservation. An important part of the domestication syndrome in erect knotweed is the elimination of germination heteromorphism: domesticated erect knotweed produced almost no tubercled achenes, instead producing smooth achenes that germinate more reliably and contain less inedible material (Mueller 2017d). Can the sample proportions (\% smooth achenes) of carbonized assemblages be taken at face value, or is one morph more likely to be preserved via carbonization than the other?

3) Assess the effects of sampling error. Small sample size is a problem in and of itself for the study of variability in a population. It is rare for entire erect knotweed achenes to be preserved; most assemblages are made up of many kernels and fragments of pericarp (Figure 1). Even if every effort is made to sample well-preserved contexts, it is rare to find a sample of $>50$ well-preserved achenes from a single well-defined context (Mueller 2017c). Estimates of population proportion derived from small samples have large margins of error, so clear guidelines are needed to recognize which assemblages are likely to be outside the natural range of variation after taking into consideration the uncertainty introduced by sampling error. This is a problem shared by any researcher who is attempting to differentiate between wild and domesticated populations on the basis of nominal variables (for example, the presence/absence of an abscission scar in cereals or the seed coat texture of chenopods).

The first two problems were addressed in a series of carbonization experiments. The effects of sampling error were explored probabilistically.

\section{Carbonization Background}

Two variables are fundamental to any carbonization experiment: temperature and duration of exposure to heat. Different seeds and fruits will carbonize with more or less exposure to heat, depending on their physical and chemical characteristics. Märkle and Rösch (2008) tested the seeds or fruits of seven 
different taxa to determine minimum conditions for inducing carbonization and maximum conditions under which diagnostic attributes of the seed or fruit would be retained. Some taxa had very small temperature ranges in which they could be carbonized without disintegrating. Oil seed crops in particular had very specific necessary conditions for preservation (2008:S260). For example, Wright (2008:145) suggests that sunflower achenes are unlikely to be preserved unless they are carbonized at temperatures somewhere between $300-440^{\circ} \mathrm{C}$. Below $300^{\circ}$ they still contain enough uncarbonized material to be susceptible to decay, and above $440^{\circ}$ they become more friable and less likely to survive. Several different varieties of wheat (Triticum spp.) and barley (Hordeum vulgare L.) have larger ranges of conditions that will lead to preservation by carbonization, both in terms of temperature and duration of exposure (Boardman and Jones 1990:5). Their comparably large survival window may contribute to their abundance at archaeological sites. A seed or fruit may be preserved by carbonization, but the characteristics of interest may be destroyed or distorted. Braadbaart and Bergen (2005) found that emmer wheat (Triticum dicoccum Schrank), bread wheat (Triticum aestivum L.), and durum wheat (Triticum durum Desf.) can be distinguished from one another on the basis of aspect ratio (called slenderness in their study). But the characteristic shapes of each type of wheat disappear when they are heated at $290^{\circ} \mathrm{C}$, making their identification to species impossible. For this study, I had to take into particular consideration the preservation of the pericarp, the characteristics of which are fundamental to the study of erect knotweed domestication. Temperature and duration of exposure needed to be set at levels that would consistently preserve the pericarp.

When plant tissues are carbonized, they generally shrink as water and oils evaporate and other tissue constituents change chemical structure. To account for this shrinkage, the use of carbonization correction factors is common, especially in domestication studies where seed and fruit size is often the object of study. For the EAC domesticates sumpweed and sunflower, correction factors were derived from average shrinkage in carbonization experiments and applied as multipliers to the length and width of carbonized assemblages (Asch and Asch 1978; Powell 2000; Tarighat et al. 2011; Yarnell 1972; 1978; 
Smith 2014; Wright 2008). This method is employed to approximate size change, even though experiments have shown that multiple factors, especially temperature and duration of heat exposure, affect post-carbonization size (Braadbart and Wright 2007). Temperature and duration of heat exposure lead to differential deformation, but few methods are available to reconstruct carbonizing conditions in order to take this variation into account (but see Braadbart et al. 2004; Braadbart et. al. 2007; Braadbart and Wright 2007). For erect knotweed, there is relatively small temperature window in which whole achenes will be preserved, but the carbonization corrections derived by these experiments should still be seen as preliminary estimates to be refined by future studies.

The chemical composition of seeds and fruits can also determine how they are affected by carbonization. For example, Braadbart and Wright (2007) used an heirloom variety of sunflower seeds for their study because modern commercial varieties have been bred to increase oil content. This is problematic if the goal is to compare them to ancient varieties with lower oil content because lipids evaporate rather than carbonize. Fat content of the seed or fruit will thus affect how much it shrinks when carbonized (Braadbart et al. 2007). Studying a closely related species of knotweed, Yurtseva (2001) has shown that the pericarp of the tubercled achenes is thicker than that of the smooth achenes partly because it is fortified with layers of wax, which are absent in smooth achenes. Wax (a lipid) is not at all likely to be preserved by carbonization, so tubercled achenes can be expected to shrink more than smooth ones. On the other hand, smooth morphs (since they are not protected by layers of moisture-retardant wax) are likely to have a higher water content. Since water evaporates during carbonization, this might offset the difference. Asch and Asch (1985:144), in what are only described as "preliminary experiments," found that the length of both morphs decreased by $20 \%$ when carbonized, but that the width of smooth morphs was not affected, whereas the width of tubercled morphs also decreased by $20 \%$.

\section{Materials and Methods}

\section{Phase I}


From observing archaeological collections, it is clear that many carbonized erect knotweed achenes become puffed or popped as they are subjected to heat (Figure 1). Parts of their perisperm bubble through the pericarp, obscuring their shape and size. When this occurs, the pericarp usually splits into pieces and falls away from the kernel (Figure 1). Pericarp fragments and kernels are commonplace in archaeological assemblages, but these fruit parts are not very useful for the purposes of identifying domestication syndrome in erect knotweed. The goal of Phase 1 was to determine the temperature threshold at which pericarps begin to fracture and disintegrate.

I carbonized batches of erect knotweed achenes to determine what temperature resulted in assemblages of undistorted achenes. I pulled four groups of five achenes each from herbarium specimens and removed their perianths (adhering flower parts, see Figure 1) before photographing them. I then embedded them in quartz sand in aluminum containers, covering each achene with sand grains to provide near-anoxic conditions. I fired them at $250,275,300$, and $325^{\circ} \mathrm{C}$ for 30 minutes. All the achenes fired above $300^{\circ} \mathrm{C}$ were puffed or popped, whereas none of the achenes fired at or below $300^{\circ} \mathrm{C}$ were, so I set the temperature for the larger experiment at $300^{\circ} \mathrm{C}$. Phase I suggests that the window of sufficient conditions for achene preservation is quite narrow: any fruits subjected to temperatures above $300^{\circ} \mathrm{C}$ are likely to be represented by kernels and pericarp fragments in archaeological samples.

\section{Phase II}

The goal of Phase II was to determine how carbonization affected the size and shape of erect knotweed achenes in general, and if there were differential effects depending on 1) pericarp texture; 2) achene size; or 3) achene maturity. I selected 50 tubercled and 50 smooth morphs from a batch harvested at the Bellows Creek Farm, Jefferson County, MO, on October 30, 2015 (Mueller 2017d). At the time of the experiment, these achenes had been in cold storage for about 9 months. Of these, 25 of each were mature and 25 were immature. Mature and immature in the context of this experiment refer to whether or not the pericarp could be deformed by pressing it with a metal tool, not to their viability. Greenhouse experiments have shown that "immature" achenes are often viable. Maturity still seems to be a reasonable 
adjective to describe this attribute, though, since the softness of the pericarp is developmental and the proportion of mature (hard pericarp) achenes increases as the season progresses (Mueller 2017d). Each achene was given a unique number and stored in a separate, labeled capsule throughout the experiment.

I photographed each achene with its perianth intact (Figure 1) because I also wanted to see what effect carbonization would have on perianth preservation. In archaeological assemblages of carbonized seeds, it is very uncommon for any part of the perianth to be preserved, yet it seemed likely that many erect knotweed achenes retained their perianth up until the time that they were carbonized for two reasons. First, in the only large, uncarbonized assemblage of archeological erect knotweed available, the Whitney Bluff site assemblage, $75 \%$ retain some or all of their perianth. Second, it seems time consuming and pointless to remove the perianth from erect knotweed achenes without also fracturing or removing the pericarp. The tough pericarp presents more of barrier to digestion than the open, papery perianth. If ancient farmers were successful in removing the pericarp, the perianth would also be eliminated as a matter of course, so there would be little reason to remove the perianth but not the pericarp. The most parsimonious explanation for the lack of perianths on carbonized archaeological specimens seemed to be that they are easily destroyed during carbonization.

After they were photographed, achenes were transferred to ceramic crucibles, covered in quartz sand, and fired for 30 minutes in a muffle furnace pre-heated to $300^{\circ} \mathrm{C}$. Each achene was then photographed again. Both pre- and post-carbonization images were subjected to the morphometric analysis to ascertain changes in both shape and size. Morphometric measures were taken using ImageJ open source image analysis software; formulas are given in Table 1.

\section{Phase III}

Given the major differences in the chemical composition and structure of the pericarps of smooth and tubercled morphs, I wanted to know if one was more likely to preserve via carbonization than the other. I carbonized 100 achenes of each morph, 50 each at $300^{\circ} \mathrm{C}$ and $350^{\circ} \mathrm{C}(\mathrm{n}=200)$. I then counted how 
many of each type retained an intact pericarp, how many were popped, and how many pericarps had completely fractured leaving only a kernel.

\section{Receptacle, and Perianth base.}

Two different types of well-preserved achenes occur. Type 1 consists of only the achene proper, and Type 2 consists of the achene and an adhering receptacle covered in remnants of the perianth referred to here as the perianth base (Figure 1). A receptacle is a thickened portion of a stem to which the fruit adheres. In the case of erect knotweed, it is usually covered by pieces of perianth (outer flower parts, commonly referred to as petals) that adhere to the mature fruit. Achenes lacking perianth bases will be, on average, shorter and smaller than those with preserved perianth bases, as well as differently shaped. I developed a set of correction factors for achenes missing their perianth base so that I could include both types in the morphometric analysis that were part of a larger study (Mueller 2017c). The application of these correction factors increased the number of measurable archaeological achenes in the assemblages I analyzed from 747 to 1,267 , and can be employed in future morphological studies of this crop species in order to maximize sample size. To develop the corrections, I photographed and measured twenty achenes of both morphs from modern populations before and after removing their perianth base.

\section{Carbonization experiments: Results}

\section{Morphology}

Size. The effects of carbonization on the size of achenes are pronounced. By any measure, both morphs shrink significantly ( $\mathrm{p}=>0.0001$ for change in area, length, width, and LXW for both morphs). But this effect is not uniform between the two morphs. Tubercled morphs shrink more, averaging only $70 \%$ of their previous area, whereas smooth morphs average $76 \%$. This difference is not a result of size differences between the two morphs: there is a very low correlation between original area and percentage remaining $\left(\mathrm{r}^{2}=0.106\right)$. It is likely that differential shrinkage rate between the two morphs is caused by the composition of the pericarp itself. This conclusion is further supported by the fact that there are 
differences between how mature and immature achenes are effected by carbonization. In both morphs, soft, immature achenes whose pericarps haven't finished developing shrink less than fully developed achenes. The recommended correction factors reported in Table 2 are derived from the pooled effects on mature and immature achenes. They are thus probably conservative since ancient harvests taken in late October or early November, when the seeds are most abundant and easy to remove, are unlikely to have contained many immature achenes.

Shape. Carbonization also affects achene shape. Differential effects between the two morphs are present but subtle. The aspect ratio of smooth morphs is not significantly different before and after carbonization $(\mathrm{p}=0.8634)$, whereas the aspect ratio of tubercled morphs decreases an average of 0.10 , and this difference is significant $(\mathrm{p}=0.0001)$. This makes sense because the minor axis is differentially effected by carbonization between the two morphs (Table 3). The same is true of achene roundness: tubercled morphs roundness increases significantly, on average 0.50 (Table 4; $\mathrm{p}=0.0001$ ), and smooth morphs do not change significantly one way or the other (Table 4; $\mathrm{p}=0.2741$ ). But carbonization correction factors should not be used for aspect ratio or roundness because for both of these measures one standard deviation from the mean difference before and after carbonization includes both positive and negative values - i.e. shape, as measured by these descriptors, does not change in a predictable manor due to carbonization (Table 4).

The most sensitive measure of shape deployed here is circularity, because it measures the relationship between area and perimeter, rather than relying on single point-to-point distances across the shape. Probably due to its greater sensitivity, circularity is the most effective shape descriptor for quantifying the slight differences in shape that result from carbonization. The circularity of both morphs increases significantly ( $\mathrm{p}=0.0007$ for smooth morphs, $\mathrm{p}=0.0004$ for tubercled morphs; Table 4 ). Change in circularity is correlated with original circularity (Figure 2): the most circular achenes change shape less, whereas the least circular achenes gained the most circularity with carbonization. The effect is that the same assemblage of achenes is more homogenous with a smaller range of circularity values after 
carbonization than it was before carbonization. A simple additive correction factor using the average change in circularity overcorrects and yields a reconstructed mean that is too low (Table 5). A more accurate correction factor was derived from the equation of the least-squares regression line fit to a plot of post-carbonization circularity versus change in circularity $\left(\mathrm{C}_{1}-\mathrm{C}_{2}\right)$ (Figure 2$)$. I solved the equation of the least squares regression line for change in circularity (the unknown variable for archaeological assemblages):

$$
\mathrm{C}_{2}=0.503-0.486^{*}\left(\mathrm{C}_{1}-\mathrm{C}_{2}\right) \rightarrow \mathrm{C}_{1}-\mathrm{C}_{2}=\left(\mathrm{C}_{2}-0.503\right) /-0.486
$$

The expected change in carbonization for a particular achene can be calculated and applied to its postcarbonization circularity to reconstruct its original circularity using the following formula:

\section{$C_{1}=\left[\left(C_{2}-0.503\right) /-0.486\right]+C_{2}$}

I checked this correction factor using the known values for the pre-carbonization assemblage. It calculated the mean circularity of the assemblage to within .01 of the real value (Table 5).

Receptacle, and Perianth base. There was a significant difference between the size of the perianth bases between the two morphs: the smooth morph perianth base accounts for a smaller percentage of total achene area than does the perianth base of the tubercled morph, and is smaller in absolute terms (Table 6). Not surprisingly, removing the perianth base also changes the shape of the achene (Table 6). Here, aspect ratio and roundness show more clear differences than does circularity because the shape of the achene mostly changes in that its major axis is reduced when the perianth base is removed. Recommended correction factors are given in Table 2 .

\section{Preservation}

The perianth is almost never preserved on archaeological carbonized specimens. At the outset of this experiment I considered it likely that the perianth was destroyed by carbonization. Results suggest that, to the contrary, the perianth is not at all likely to be destroyed by carbonization, at least under the 
conditions used in this study. Of 100 achenes carbonized in Phase III, 36 retained their entire perianth after carbonization, and 60 retained parts of it. Only 4 completely lacked a perianth as a result of carbonization. It is possible that a different firing temperature or duration would destroy the perianth, or that taphonomic processes after carbonization removed the perianths from carbonized archaeological specimens. Still, the fact that perianth fragments are extremely rare on carbonized archaeological specimens and are almost universally retained on experimentally carbonized achenes suggests that perianth removal may have been a processing task prior to and separate from pericarp fracturing or removal.

Differential preservation of smooth and tubercled pericarps. At $300^{\circ} \mathrm{C}$, smooth morphs were slightly more likely to fracture (Figure 3). At $350^{\circ} \mathrm{C}$, the difference in preservation between the two morphs increased greatly: only 4/50 smooth achenes remained intact, compared to 27/50 tubercled achenes (Figure 3). We can thus expect tubercled morphs to be preserved in carbonized assemblages in greater numbers than smooth morphs. Until methods for reconstructing the carbonizing conditions that effected particular assemblages improve, it will be impossible to correct for this differential preservation quantitatively. Qualitatively, this result makes the existence of carbonized assemblages composed primarily of smooth morphs all the more compelling evidence of domestication: it is highly unlikely that such assemblages are the result of a preservation bias. On the contrary, this indicator of domestication is evident in spite of a preservation bias that would tend to obscure it.

\section{Sampling Bias}

Accurately Estimating Population Proportion. Population proportion is the percentage of a given population that has a particular nominal (non-continuous) characteristic. Sample proportion is the percentage of a given sample that has that characteristic. In the case of erect knotweed domestication, the characteristic of interest is the percentage of a given harvest made up of smooth morphs. I sampled populations of erect knotweed between mid-October and mid-November over two growing seasons in order to estimate the range of normal population proportions of smooth morphs for erect knotweed (Table 
7; see also Mueller 2017d). There was a large range of sample proportions in modern erect knotweed, from $29-72 \%$ smooth morphs at sample sizes varying from 814-3011 achenes. Figure 4 shows the sample size necessary to estimate population proportion with a $5 \%$ margin of error at $95 \%$ confidence for different population proportions. It is more difficult to accurately predict population proportions close to $50 / 50$ than it is to estimate highly skewed population proportions, but the sample sizes necessary for estimates at this level of accuracy even for skewed populations are larger than most of the archaeological samples of erect knotweed available.

Archaeologists cannot dictate sample size but must instead account for the error and uncertainty inherent to our small samples. I calculated the margin of error for different sample sizes at $95 \%$ confidence for three hypothetical populations of erect knotweed: 1) an assemblage made up of 90\% smooth morphs, which is outside of the natural range of variation and constitutes evidence for domestication; 2) an assemblage made up 75\% smooth morphs, which is just over the highest observed wild population proportion; and 3) an assemblage that is 50\% smooth morphs and 50\% tubercled morphs, normal for wild erect knotweed (Figure 4). Given the large margins of error, we can expect samples of ten from all three hypothetical populations to overlap. That is, even if all ten in the sample are smooth morphs, the sample could very easily come from a normal wild population (Figure 4). Because of the dynamic relationship between observed sample proportion, sample size, and margin of error, I decline to set a sample proportion above which an assemblage is domesticated and below which it is wild. The sample proportion should be assessed along with assemblage size for each individual case, as, for example, in the following case study (see also Mueller 2017c).

Case Study: The Westpark Assemblage. The largest archaeological assemblage that I analyzed came from Feature 300 of the Westpark site, IL. Westpark is a multi-component site that was occupied from at least c. cal. 650 -- 1100 CE) (Lopinot et al. 1991; Powell 2000; Mueller 2017c). A direct date on the analyzed knotweed yielded a date of cal. 1037-1183 CE (uncal. 910 BP +/- 20). ). Feature 300 was an irregular oval shaped pit. The bottom $2-5 \mathrm{~cm}$ of the pit contained a homogenous mass of erect knotweed 
kernels and achenes. For my initial morphometric analysis, I randomly sub-sampled 100 achenes from the tens of thousands that were recovered from this context. These achenes are significantly larger, on average, than my modern comparative sample (Mueller 2017c). The proportion of smooth morphs in this first sub-sample was $81 \%$, somewhat outside of the natural range of variation, but within the $95 \%$ confidence estimate for a population proportion of $75 \%$ with a sample of 100 (Figure 4). I took advantage of this unusually large assemblage to independently confirm the confidence and accuracy estimates generated mathematically. An additional 20 random samples of 10 yielded sample proportions ranging widely from $30-100 \%$ smooth morphs - exactly as predicted if the true population proportion was $\sim 75 \%$ smooth morphs. Ten random samples of 20 yielded sample proportions of $70-90 \%$, again as predicted by the laws of probability.

For the entire sample of 500 that this process yielded, the Westpark assemblage sample proportion was $78 \%$ smooth morphs. Since a sample of 500 is more than is required for a $5 \%$ confidence margin no matter what the true population proportion (Figure 4), this means that the Westpark assemblage has at least a slightly higher proportion of smooth morphs than has been observed in a wild population: somewhere between 73-83\% smooth morphs. Considering that smooth morphs are likely to be systematically underrepresented in carbonized assemblages due to differential preservation (Figure 3), this sample proportion constitutes equivocal evidence for the effects of human selection at the Westpark site. Taken together with the fact that the Westpark achenes are significantly larger than is normal for erect knotweed, and come from a context that clearly indicates large scale cultivation (Powell 2000), a strong case can be made for domestication at this site.

\section{Conclusions}

The analyses reported here were conducted primarily to facilitate the study of a particular crop: erect knotweed. But the issues raised pertain to other studies of plant domestication using archaeological assemblages in several ways. Previous studies have shown that carbonization can affect the shape and size of seeds differently depending on the composition of the seed, duration of exposure to heat, and fire 
temperature. Carbonization can also lead to differential preservation, biasing the archaeological record and sometimes eliminating the very characters necessary for recognizing a species or domesticated subspecies. Both of these effects present problems for the study of domestication through morphology. But in this case, the narrow window of conditions under which the pericarp is preserved helps narrow down the possible effects of carbonization on erect knotweed achenes. Experiments showed that the pericarp of erect knotweed achenes, especially on smooth morphs, is unlikely to survive intact at temperatures above $300^{\circ} \mathrm{C}$. This means that carbonization corrections derived from low-temperature fires $\left(300^{\circ} \mathrm{C}\right.$ in this study) are likely to be accurate for all well-preserved archaeological assemblages, because specimens burned in hotter fires are probably only preserved in the form of kernels. Such triangulation may be possible for other crop species as well.

Variation in the effects of carbonization has led some researchers to call for the use of nominal (present/absent) characteristics to argue for domestication (Wright 2003). The state of the art in cereal domestication studies is to use the presence or absence of non-shattering inflorescences as an indicator of domestication, either along with seed size or independently of it (i.e. Fuller et al. 2009; Tanno and Wilcox 2012). For chenopods, seed coat texture and margin configuration are crucial nominal characteristics for identifying taxa and for distinguishing between wild and domesticated assemblages (Bruno 2006; Fritz and Smith 1988), and some researchers have used the sample proportions of wild and domesticated types to argue for divergent management practices (and thus crop evolution) between communities (Gremillion 1993). For erect knotweed, the nominal characteristic of interest is the proportion of smooth morphs in a population. Because wild erect knotweed also produces smooth morphs, their presence alone does not suggest domestication. While this may seem like a problem unique to erect knotweed, it is not. The characteristics associated with domestication (testa characteristics and margin configuration for chenopods, tough rachises in cereals) are also present at low frequencies in wild populations, and become more common over time as selective pressures associated with cultivation begin to leave their mark. 
For each domesticate, it is necessary to determine what sample proportion (at what sample size) is necessary to recognize an assemblage that is outside the range of variation for wild plants. In some cases, this will probably involve first establishing what that range of natural variation is. The characterization of erect knotweed variability presented here and elsewhere (Mueller 2017d) should be considered preliminary. Harvest proportions of smooth morphs varied from $29 \%-72 \%$ across two growing seasons and two populations - such variance requires explanation. The same problem applies to another EAC crop, goosefoot (C. berliandieri) in ENA. The syndrome of domestication includes, among other characters, a reduction in testa thickness. Specimens exhibiting this characteristic are similar to "red morph" - a thin-testa seed type present in small proportions on wild plants (Fritz and Smith 1988). Very few studies have attempted to quantify the frequency of red morphs in wild populations. Asch and Asch (1985:179-180) state that "most wild plants have at least a few" of this type, but they also encountered a population in which the red morph predominated. Their subsequent harvests convinced them that this condition was rare and probably resulted from unusual growing conditions. Smith (1985:122) made a collection of 5,736 fruits from four different populations. Red morphs constituted 1-3\% of these samples. As for erect knotweed smooth morphs, a much larger sampling effort could be made to determine what genetic or environmental factors govern the production of red morphs.

For wheat and barley, even if we assume that wild populations originally had negligible proportions of domesticated types on the theoretical grounds that such a trait would be maladaptive (Hillman and Davies 1990:167), changes over time in the population proportion of brittle to tough rachises are used to track the process of domestication (i.e. Asouti and Fuller 2012; 2013). The same is true for rice; for example, a shift from $27.3 \%$ domesticated type to $38.8 \%$ domesticated type over $\sim 300$ years at one site has been reported as evidence of the process of domestication (Fuller et. al. 2009). Such subtle shifts in population proportion are only detectable with very large samples $(>100)$ that are at least arguably drawn from the same living population. Aggregating many small samples from across an entire site to estimate population proportion may lead to large sampling errors. The more evenly mixed an 
assemblage is between domesticated and wild types, the greater the margin of error (Figure 4) and potential for mistaking sampling error for a real trend, and the larger the sample needed to recognize subtle changes in proportion confidently.

The correction factors and sampling models presented here should be of use to paleoethnobotanists who wish to assess where their assemblages of erect knotweed fall on the continuum between wild and domesticated. I expect that both experimental corrections and assessments of variability in wild populations will be refined and amended by future studies, but the analyses presented here should allow researchers to track the process of erect knotweed domestication in the archaeological record, thus adding to our knowledge of agricultural practice across ancient ENA.

\section{Acknowledgements}

Support for this project was provided by US National Science Foundation Doctoral Dissertation Improvement Grant \#58292, the Wenner-Gren Foundation, and the Lynne Cooper Harvey Fellowship in American Culture Studies at Washington University. I would also like to thank

Gayle J. Fritz and Richard J. Smith who read earlier versions of this paper and provided valuable feedback, and George Yatskievych for his willingness to clear up knotty questions about what to call various parts of fruits and seeds.

Conflict of Interest: The author declares that she had no conflict of interest.

\section{Works Cited}

Asch, David L. and Nancy B. Asch 
1985 Prehistoric Plant Cultivation in West Central Illinois. In Prehistoric Food Production in North America, edited by Richard I. Ford, pp. 149-203. Anthropological Papers. vol. 75. Museum of Anthropology, University of Michigan, Ann Arbor, MI.

Asch, Nancy B. and David L. Asch

1978 The Economic Potential of Iva annua and its Prehistoric Importance in the Lower Illinois Valley. In The Nature and Status of Ethnobotany, edited by Richard A. Ford, pp. 301343. Anthropological Papers. vol. 67. Museum of Anthropology, University of Michigan, Ann Arbor, MI.

Asouti, Eleni and Dorian Q. Fuller

2012 From Foraging to Farming in the Southern Levant: The Development of Epipalaeolithic and Pre-Pottery Neolithic Plant Management Strategies. Vegetation History and Archaeobotany 21(2):149-162.

2013 A Contextual Approach to the Emergence of Agriculture in Southwest Asia. Current Anthropology 54(3):299-345.

Boardman, Sheila and Glynis Jones

1990 Experiments on the effects of charring on cereal plant components. Journal of Archaeological Science 17(1):1-11.

Braadbaart, Freek, Jaap J Boon, H Veld, P David and Pim F van Bergen

2004 Laboratory simulations of the transformation of peas as a result of heat treatment: changes of the physical and chemical properties. Journal of Archaeological Science 31(6):821-833.

Braadbaart, Freek and Pim F van Bergen

2005 Digital imaging analysis of size and shape of wheat and pea upon heating under anoxic conditions as a function of the temperature. Vegetation History and Archaeobotany 14(1):67-75.

Braadbaart, Freek and Patti J. Wright

2007 Changes in Mass and Dimensions of Sunflower (Helianthus annuus L.) Achenes and Aeeds Due to Carbonization. Economic Botany 61(2):137-153.

Bruno, Maria C.

2006 A Morphological Approach to Documenting the Domestication of Chenopodium in the Andes. In Documenting Domestication: New Genetic and Archaeological Paradigms, edited by Melinda A Zeder, Daniel G. Bradley, Eve Emshwiller and Bruce D Smith, pp. 32-45. University of California Press, Berkeley. 
Childs, Dylan Z., C.J.E. Metcalf and Mark Rees

2010 Evolutionary Bet-Hedging in the Real World: Empirical Evidence and Challenges Revealed by Plants. Proceedings of the Royal Society of London B: Biological Sciences rspb20100707:1-10.

Crites, Gary D.

1993 Domesticated Sunflower in the Fifth Millennium B.P. Temporal Context: New Evidence from Middle Tennessee. American Antiquity 58(1):146-148.

Fritz, Gayle J.

1986 Prehistoric Ozark Agriculture:The University of Arkansas Rockshelter Collections. Dissertation, Anthropology, University of North Carolina, Chapel Hill.

1993 Early and Middle Woodland Period Paleoethnobotany. In Foraging and Farming in the Eastern Woodlands, edited by C. Margaret Scarry, pp. 39-56. University Press of Florida, Gainesville.

Fritz, Gayle J. and Bruce D. Smith

1988 Old Collections and New Technology: Documenting the Domestication of Chenopodium in Eastern North America. Midcontinental Journal of Archaeology 13(1):3-27.

Fuller, Dorian Q., Ling Qin, Yunfei Zheng, Zhijun Zhao, Xugao Chen, Leo Aoi Hosoya and Sun. GuoPing

2009 The Domestication Process and Domestication Rate in Rice: Spikelet Bases from the Lower Yangtze. Science 323:1607-1610.

Gremillion, Kristen J.

1993 The Evolution of Seed Morphology in Domesticated Chenopodium: An Archaeological Case Study. Journal of Ethnobiology 13:149-169.

Kay, Marvin, Francis B. King and Christine K. Robinson

1980 Cucurbits from Phillips Spring: New Evidence and Interpretations. American Antiquity 45(4):806-822.

Lopinot, Neal H., Gayle J. Fritz and John E. Kelly

1991 The Archaeological Context and Significance of Polygonum erectum Achene Masses from the American Bottom Region. Proceedings of the 14th Annual Society for Ethnobiology Conference. St. Louis.

Märkle, Tanja and Manfred Rösch 
2008 Experiments on the effects of carbonization on some cultivated plant seeds. Vegetation history and archaeobotany 17(1):257-263.

Mueller, Natalie G.

2017a Documenting Domestication in a Lost Crop (Polygonum erectum L.): Evolutionary BetHedgers Under Cultivation. Vegetation History and Archaeobotany.

2017b An Extinct Domesticated Subspecies of Erect Knotweed in Eastern North America: Polygonum erectum L. ssp. watsoniae (POLYGONACEAE). Novon 25(2).

2017c Seeds as Artifacts of Communities of Practice: The Domestication of Erect Knotweed in Eastern North America. Dissertation, Anthropology, Washington Universtiy in St. Louis, Saint Louis, MO.

2017d Bet-Hedgers Under Cultivation: Investigating the Domestication of Erect Knotweed (Polygonum erectum L.) using Growth Experiments. Human Ecology.

Powell, Gina

2000 Charred, Non-Maize Seed Concentrations in the American Bottom Area: Examples from the Westpark Site (11-MO-96), Monroe County, Illinois. Midcontinental Journal of Archaeology 25(1):27-48.

Silvertown, Jonathan W

1984 Phenotypic Variety in Seed Germination Behavior: The Ontogeny and Evolution of Somatic Polymorphism in Seeds. American Naturalist 124(1):1-16.

Simon, Mary L. and Kathryn E. Parker

2006 Prehistoric Plant Use in the American Bottom: New Thoughts and Interpretations. Southeastern Archaeology 25(2):212-257.

Slatkin, Montgomery

1974 Hedging One's Evolutionary Bets. Nature 250:704-705.

Smith, Bruce D.

1985 Chenopodium berlandieri ssp. jonesianum: evidence for a Hopewellian domesticate from Ash Cave, Ohio. Southeastern Archaeology 4(2):107-133.

1992 Rivers of Change: Essays on Early Agriculture in Eastern North America. Smithsonian Institution Press, Washington. 
2006 Eastern North America as an Independent Center of Plant Domestication. Proceedings of the National Academy of Sciences 103(33):12223-12228.

2014 The Domestication of Helianthus annuus L. (Sunflower). Vegetation History and Archaeobotany 23(1):57-74.

Smith, Bruce D. and Vicki A. Funk

1985 A Newly Described Subfossil Cultivar of Chenopodium (Chenopodiaceae). Phytologia 57(7):445-448.

Smith, Bruce D. and Richard A. Yarnell

2009 Initial Formation of an Indigenous Crop Complex in Eastern North America at 3800 B.P. Proceedings of the National Academy of Sciences 106(16):6561-6566.

Tanno, Ken-ichi and George Willcox

2012 Distinguishing Wild and Domestic Wheat and Barley Spikelets from Early Holocene Sites in the Near East. Vegetation History and Archaeobotany 21(2):107-115.

Tarighat, Somayeh S., David L. Lentz, Stephen F. Matter and Robert Bye

2011 Morphometric Analyis of Sunflower (Helianthus annuus L.) Achenes from Meixco and Eastern North America. Economic Botany 65(3):260-270.

Volney, Jones H.

1936 The Vegetal Remains of Newt Kash Hollow Shelter. In Rock Shelters of Menifee County, Kentcucky, edited by W.S. Webb and W.D. Funkhouser, pp. 147-165. vol. 3. University of Kentcuky Reports in Archaeology and Anthropology, Lexington.

Wright, Patti J.

2003 Preservation or destruction of plant remains by carbonization? Journal of Archaeological Science 30(5):577-583.

2008 Understanding the Carbonization and Preservation of Sunflower and Sumpweed Remains. Midcontinental Journal of Archaeology 33(2):139-153.

Yarnell, Richard A.

1972 Iva annua var. macrocarpa: Extinct American Cultigen? American Anthropologist 74:335-341. 
1978 Domestication of Sunflower and Sumpweed in Eastern North America. In The Nature and Status of Ethnobotany, edited by Richard A. Ford, pp. 289-299. Anthropological Papers No. 67. Museum of Anthropology, Univerity of Michigan, Ann Arbor, MI.

\section{Yurtseva, O.V.}

2001 Ultrasculpture of Achene Surface in Polygonum section Polygonum (Polygonaceae) in Russia. Nordic Journal of Botany 21(4):513-528. 
Table 1: Morphometric Measurements

\begin{tabular}{|l|l|l|}
\hline Measurements & Description & Procedure/Formula \\
\hline Area & \# of pixels within the margins of object & $\begin{array}{l}\text { Select image of achene, area measured in } \\
\mathrm{mm}^{2}\end{array}$ \\
\hline Length & \#of pixels along major axis of selected object & Draw line to measure length in mm \\
\hline Width & Number of pixels along minor axis of selected object & Draw line to measure length in $\mathrm{mm}$ \\
\hline Shape Factors & $\begin{array}{l}\text { Degree of elongation; major axis divided by (mean of }) \\
\text { minor axis (axes). Axes derived from an ellipse fitted } \\
\text { around the selected object. }\end{array}$ & [Major axis]/[Minor axis] \\
\hline Aspect Ratio & $\begin{array}{l}\text { Roughly inverse of aspect ratio, a measure of elongation of } \\
\text { the major axis with respect to the object's area. Axis } \\
\text { derived from an ellipse fitted around the selected object. }\end{array}$ & 4 Area]/( $\pi \mathrm{x}$ [Major axis] \\
\hline Roundness & $\begin{array}{l}\text { Relationship between perimeter and area; degree of } \\
\text { departure from a circle. } 1.0 \text { is a perfect circle, } 0.0 \text { is a } \\
\text { straight line. }\end{array}$ & $4 \pi \mathrm{x}$ [Area]/[Perimeter $]^{2}$ \\
\hline
\end{tabular}

Table 1: Gives the formulas used to generate the morphometric measures. All image analysis was completed using ImageJ open source image analysis software.

\begin{tabular}{|c|c|c|c|c|}
\hline \multicolumn{5}{|c|}{ Corrections for changes due to carbonization } \\
\hline & \multicolumn{2}{|l|}{ Smooth } & \multicolumn{2}{|l|}{ Tubercled } \\
\hline Size & $w /$ perianth & No perianth & w/perianth & No perianth \\
\hline Area & $\mathrm{A}_{2} * 1.24=\mathrm{A}_{1}$ & $\mathrm{~A}_{2} * 1.18=\mathrm{A}_{1}$ & $\mathrm{~A}_{2} * 1.30=\mathrm{A}_{1}$ & $\mathrm{~A}_{2} * 1.22=\mathrm{A}_{1}$ \\
\hline Length X Width & $\mathrm{LXW}_{2} * 1.20=\mathrm{LXW}_{1}$ & $\mathrm{LXW}_{2} * 1.17=\mathrm{LXW}_{1}$ & $\mathrm{LXW}_{2} * 1.29=\mathrm{LXW}_{1}$ & $\mathrm{LXW}_{2} * 1.23=\mathrm{LXW}_{1}$ \\
\hline \multicolumn{5}{|l|}{ Shape } \\
\hline Circularity & \multicolumn{4}{|c|}{$\mathrm{C}_{1}=\left[\left(\mathrm{C}_{2}-0.503\right) /-0.486\right]+\mathrm{C}_{2}$} \\
\hline \multicolumn{5}{|c|}{ Corrections for changes due to missing perianth base and receptacle } \\
\hline & \multicolumn{2}{|l|}{ Smooth } & \multicolumn{2}{|l|}{ Tubercled } \\
\hline Area & \multicolumn{2}{|l|}{$\mathrm{A}_{\text {no receptacle }} * 1.10=\mathrm{A}_{1}$} & \multicolumn{2}{|l|}{$\mathrm{A}_{\text {no receptacle }} * 1.13=\mathrm{A}_{1}$} \\
\hline Length & \multicolumn{2}{|l|}{$\mathrm{L}_{\text {no receptacle }} * 1.12=\mathrm{L}_{1}$} & \multicolumn{2}{|l|}{$\mathrm{L}_{\text {no receptacle }} * 1.17=\mathrm{L}_{1}$} \\
\hline Aspect ratio & \multicolumn{2}{|l|}{$\mathrm{AR}_{\text {no receptacle }}+0.14=\mathrm{AR}_{1}$} & \multicolumn{2}{|c|}{$\mathrm{AR}_{\text {no receptacle }}+0.19=\mathrm{AR}_{1}$} \\
\hline Roundness & \multicolumn{2}{|l|}{$\mathrm{R}_{\text {no receptacle }}-0.03=\mathrm{R}_{1}$} & \multicolumn{2}{|l|}{$\mathrm{R}_{\text {no receptacle }}-0.10=\mathrm{R}_{1}$} \\
\hline
\end{tabular}

Table 2: Recommended correction factors. Correction factors are only suggested for aspects of shape and size that change significantly and predictably (i.e. change is always in the same direction). See Results for more detailed discussion. 


\begin{tabular}{|c|c|c|c|}
\hline \multicolumn{4}{|c|}{ Table 3: Effects of Carbonization on Size } \\
\hline \multicolumn{2}{|l|}{$\mathrm{N}=100$} & Smooth & Tubercled \\
\hline \multirow[t]{2}{*}{ Area } & Mean \pm Std. Dev. & $3.12 \pm 0.467$ & $3.41 \pm 0.489$ \\
\hline & Std. Err. of Mean & 0.0674 & 0.0692 \\
\hline \multirow[t]{2}{*}{ Area carbonized } & Mean \pm Std. Dev. & $2.37 \pm 0.396$ & $2.37 \pm 0.367$ \\
\hline & Std Err of Mean & 0.0571 & 0.0518 \\
\hline \multirow[t]{2}{*}{ \% remaining } & Mean \pm Std. Dev. & $0.76 \pm 0.089$ & $0.70 \pm 0.080$ \\
\hline & Std Err of Mean & 0.0128 & 0.0113 \\
\hline \multirow[t]{2}{*}{ Length } & Mean \pm Std. Dev. & $3.12 \pm 0.254$ & $2.83 \pm 0.183$ \\
\hline & Std Err of Mean & 0.0366 & 0.0259 \\
\hline \multirow[t]{2}{*}{ Length carbonized } & Mean \pm Std. Dev. & $2.81 \pm 0.237$ & $2.47 \pm 0.193$ \\
\hline & Std Err of Mean & 0.0342 & 0.0273 \\
\hline \multirow[t]{2}{*}{ \% remaining } & Mean \pm Std. Dev. & $0.90 \pm 0.036$ & $0.87 \pm 0.042$ \\
\hline & Std Err of Mean & 0.0052 & 0.0060 \\
\hline \multirow[t]{2}{*}{ Width } & Mean \pm Std. Dev. & $1.6 \pm 0.189$ & $1.90 \pm 0.226$ \\
\hline & Std Err of Mean & 0.0272 & 0.0319 \\
\hline \multirow[t]{2}{*}{ Width carbonized } & Mean \pm Std. Dev. & $1.43 \pm 0.212$ & $1.53 \pm 0.171$ \\
\hline & Std Err of Mean & 0.0306 & 0.0241 \\
\hline \multirow[t]{2}{*}{$\%$ remaining } & Mean \pm Std. Dev. & $0.89 \pm 0.088$ & $0.81 \pm 0.080$ \\
\hline & Std Err of Mean & 0.0127 & 0.0114 \\
\hline \multirow[t]{2}{*}{$\mathrm{LX} \mathrm{W}$} & Mean \pm Std. Dev. & $5.01 \pm 0.807$ & $5.37 \pm 0.809$ \\
\hline & Std Err of Mean & 0.1164 & 0.1144 \\
\hline \multirow[t]{2}{*}{ L X W carbonized } & Mean \pm Std. Dev. & $4.02 \pm .0730$ & $3.79 \pm 0.589$ \\
\hline & Std Err of Mean & 0.1054 & 0.0834 \\
\hline \multirow[t]{2}{*}{$\%$ remaining } & Mean \pm Std. Dev. & $0.80 \pm 0.089$ & $0.71 \pm 0.089$ \\
\hline & Std Err of Mean & 0.0129 & 0.0125 \\
\hline
\end{tabular}




\begin{tabular}{|c|c|c|c|}
\hline $\mathrm{N}=100$ & & Smooth & Tubercled \\
\hline Aspect ratio $\left(\mathrm{AR}_{1}\right)$ & Mean \pm Std. Dev. & $1.94 \pm 0.254$ & $1.46 \pm 0.169$ \\
\hline & Std. Err. of Mean & 0.0366 & 0.0239 \\
\hline Aspect ratio & Mean \pm Std. Dev. & $1.93 \pm 0.368$ & $1.57 \pm 0.194$ \\
\hline carbonized $\left(\mathrm{AR}_{2}\right)$ & Std Err of Mean & 0.0531 & 0.0275 \\
\hline $\mathrm{AR}_{1}-\mathrm{AR}_{2}$ & Mean \pm Std. Dev. & $0.01 \pm 0.250$ & $-0.10 \pm 0.138$ \\
\hline & Std. Err. of Mean & 0.0361 & 0.0195 \\
\hline Roundness $\left(\mathrm{R}_{1}\right)$ & Mean \pm Std. Dev. & $0.52 \pm 0.063$ & $0.69 \pm 0.076$ \\
\hline & Std. Err. of Mean & 0.0091 & 0.0107 \\
\hline Roundness carbonized & Mean \pm Std. Dev. & $0.54 \pm 0.092$ & $0.64 \pm 0.082$ \\
\hline$\left(\mathrm{R}_{2}\right)$ & Std. Err. of Mean & 0.0133 & 0.0116 \\
\hline $\mathrm{R}_{1}-\mathrm{R}_{2}$ & Mean \pm Std. Dev. & $0.00 \pm 0.070$ & $0.05 \pm 0.062$ \\
\hline & Std. Err. of Mean & 0.0102 & 0.0088 \\
\hline Circularity $\left(\mathrm{C}_{1}\right)$ & Mean \pm Std. Dev. & $0.46 \pm 0.086$ & $0.41 \pm 0.073$ \\
\hline & Std. Err. of Mean & 0.0124 & 0.0103 \\
\hline Circularity carbonized & Mean \pm Std. Dev. & $0.52 \pm 0.060$ & $0.61 \pm 0.055$ \\
\hline$\left(\mathrm{C}_{2}\right)$ & Std. Err. of Mean & 0.0087 & 0.0078 \\
\hline $\mathrm{C}_{1}-\mathrm{C}_{2}$ & Mean \pm Std. Dev. & $-0.10 \pm 0.113$ & $-0.20 \pm 0.071$ \\
\hline & Std. Err. of Mean & 0.0164 & 0.0100 \\
\hline
\end{tabular}

\begin{tabular}{|l|r|l|r|}
\hline \multicolumn{4}{|l|}{ Table 5: Tests of circularity correction factor } \\
\hline \multicolumn{2}{|l|l|}{ Actual metrics } & Reconstructed metrics \\
\hline Mean & $\mathbf{0 . 4 3 5}$ & $\mathbf{C}=[(\mathrm{C} 2-0.503) /-0.486]+\mathrm{C}_{2}$ & $\begin{array}{l}\text { Smooth } \mathrm{C}_{1}=\mathrm{C}_{2}-0.10 \\
\text { Tubercled } \mathrm{C}_{1}=\mathrm{C}_{2}-0.20\end{array}$ \\
\hline Min & 0.62 & 0.68 & $\mathbf{0 . 4 1 4}$ \\
\hline Max & 0.23 & 0.29 & 0.52 \\
\hline Range & 0.39 & 0.38 & 0.24 \\
\hline
\end{tabular}

Table 5: Reports the results of tests on two different types of correction factors for changes in achene circularity due to carbonization: a linear function correction, and an additive correction factor. The linear function correction is able to more accurately predict the real values for the assemblage before carbonization from the post carbonization measurements. 


\begin{tabular}{|c|c|c|c|}
\hline \multicolumn{4}{|c|}{ Table 6: Effects of perianth base and receptacle size and shape } \\
\hline \multicolumn{2}{|l|}{$\mathrm{N}=20$} & Smooth & Tubercled \\
\hline \multirow[t]{2}{*}{ Area $\left(\mathrm{A}_{1}\right)$} & Mean \pm Std. Dev. & $2.42 \pm 0.264$ & $2.93 \pm 0.298$ \\
\hline & Std Err of Mean & 0.0836 & 0.0942 \\
\hline \multirow[t]{2}{*}{$\mathrm{A}_{\text {no perianth base }}$} & Mean \pm Std. Dev. & $2.19 \pm 0.252$ & $2.53 \pm 0.219$ \\
\hline & Std Err of Mean & 0.0797 & 0.0693 \\
\hline \multirow[t]{2}{*}{$\%$ remaining } & Mean \pm Std. Dev. & $0.90 \pm 0.029$ & $0.87 \pm 0.031$ \\
\hline & Std Err of Mean & 0.009 & 0.0099 \\
\hline \multirow[t]{2}{*}{$A_{1}-A_{\text {no perianth base }}$} & Mean \pm Std. Dev. & $0.23 \pm 0.071$ & $0.40 \pm 0.116$ \\
\hline & Std Err of Mean & 0.0226 & \begin{tabular}{|l|}
0.0368 \\
\end{tabular} \\
\hline \multirow[t]{2}{*}{ Length $\left(\mathrm{L}_{1}\right)$} & Mean \pm Std. Dev. & $2.94 \pm 0.201$ & $2.68 \pm 0.098$ \\
\hline & Std Err of Mean & 0.0635 & 0.031 \\
\hline \multirow[t]{2}{*}{$\mathrm{L}$ no perianth base } & Mean \pm Std. Dev. & $2.58 \pm 0.152$ & $2.23 \pm 0.132$ \\
\hline & Std Err of Mean & 0.048 & \begin{tabular}{|l|}
0.0417 \\
\end{tabular} \\
\hline \multirow[t]{2}{*}{$\%$ remaining } & Mean \pm Std. Dev. & $0.88 \pm 0.024$ & $0.83 \pm 0.044$ \\
\hline & Std Err of Mean & 0.0077 & 0.0139 \\
\hline \multirow[t]{2}{*}{$\mathrm{L}_{1}-\mathrm{L}_{\text {no perianth base }}$} & Mean \pm Std. Dev. & $0.36 \pm 0.085$ & $0.45 \pm 0.124$ \\
\hline & Std Err of Mean & 0.0268 & 0.0393 \\
\hline \multirow[t]{2}{*}{ Aspect ratio $\left(\mathrm{AR}_{1}\right)$} & Mean \pm Std. Dev. & $2.12 \pm 0.270$ & $1.46 \pm 0.118$ \\
\hline & Std Err of Mean & 0.0853 & 0.0373 \\
\hline \multirow[t]{2}{*}{$\mathrm{AR}_{\text {no perianth base }}$} & Mean \pm Std. Dev. & $1.99 \pm 0.194$ & $1.27 \pm 0.090$ \\
\hline & Std Err of Mean & 0.0612 & 0.0285 \\
\hline \multirow[t]{2}{*}{$\mathrm{AR}_{1-} \mathrm{AR}$ no perianth base } & Mean \pm Std. Dev. & $0.14 \pm 0.137$ & $0.19 \pm 0.104$ \\
\hline & Std Err of Mean & 0.0434 & 0.0328 \\
\hline \multirow[t]{2}{*}{ Roundness $\left(\mathrm{R}_{1}\right)$} & Mean \pm Std. Dev. & $0.48 \pm 0.055$ & $0.69 \pm 0.056$ \\
\hline & Std Err of Mean & 0.0175 & 0.0178 \\
\hline \multirow[t]{2}{*}{$\mathrm{R}_{\text {no perianth base }}$} & Mean \pm Std. Dev. & $0.51 \pm 0.048$ & $0.79 \pm 0.058$ \\
\hline & Std Err of Mean & 0.0153 & \begin{tabular}{|l}
0.0184 \\
\end{tabular} \\
\hline \multirow[t]{2}{*}{$\mathrm{R}_{1}-\mathrm{R}_{\text {no perianth base }}$} & Mean \pm Std. Dev. & $-0.03 \pm 0.028$ & $-0.10 \pm 0.057$ \\
\hline & Std Err of Mean & 0.0088 & 0.0179 \\
\hline \multirow[t]{2}{*}{ Circularity $\left(\mathrm{C}_{1}\right)$} & Mean \pm Std. Dev. & $0.49 \pm 0.055$ & $0.46 \pm 0.051$ \\
\hline & Std Err of Mean & 0.0175 & 0.0161 \\
\hline \multirow[t]{2}{*}{ Circularity no perianth base } & Mean \pm Std. Dev. & $0.57 \pm 0.061$ & $0.57 \pm 0.091$ \\
\hline & Std Err of Mean & 0.0193 & \begin{tabular}{|l}
0.0287 \\
\end{tabular} \\
\hline \multirow[t]{2}{*}{$\mathrm{C}_{1}-\mathrm{C}_{\text {no perianth base }}$} & Mean \pm Std. Dev. & $-0.08 \pm 0.080$ & $-0.11 \pm 0.092$ \\
\hline & Std Err of Mean & 0.0252 & 0.0290 \\
\hline
\end{tabular}


Figures

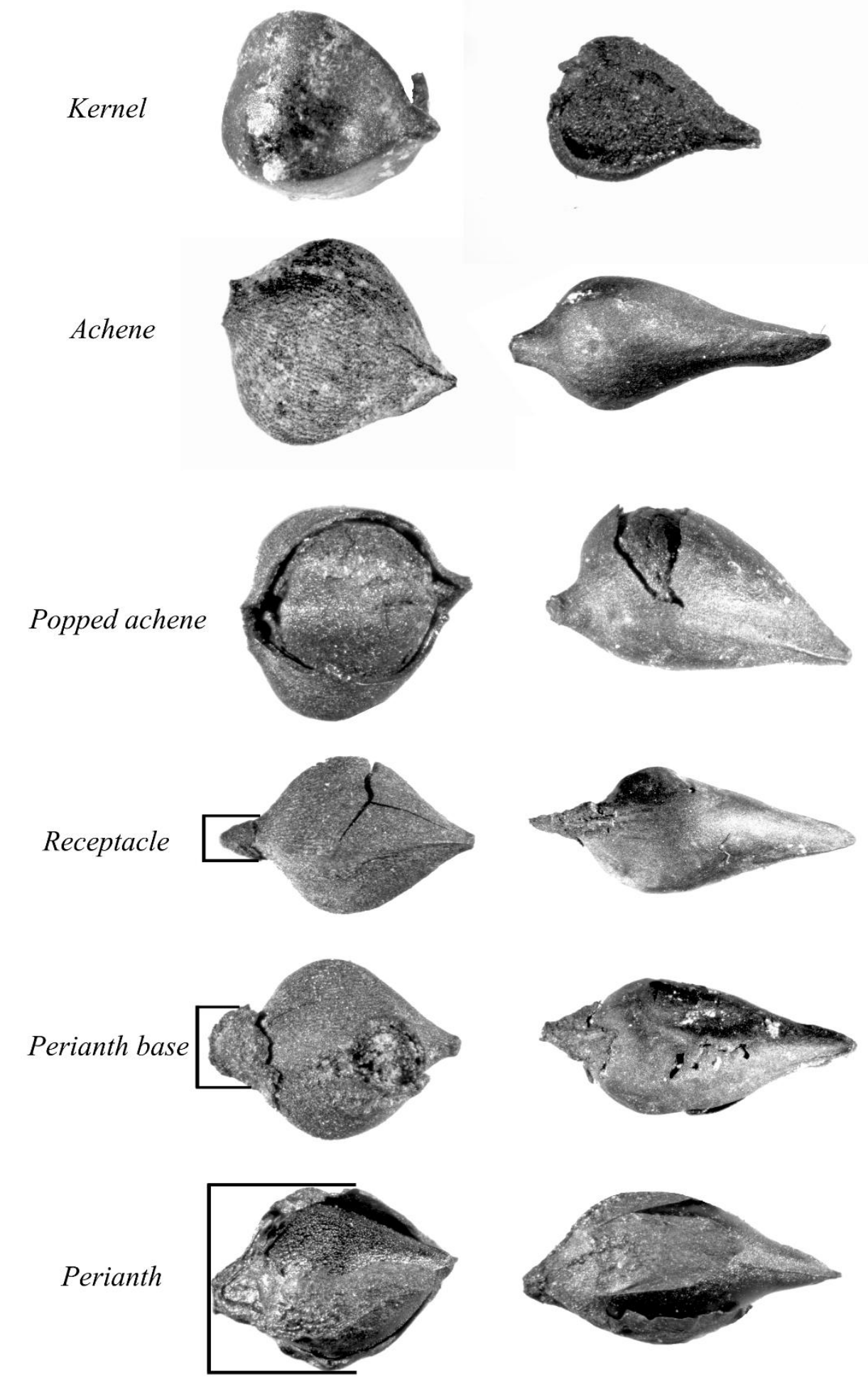


Figure 1: Shows different preservation states for carbonized erect knotweed and achene dimorphism.

Kernels are usually identified as erect knotweed by association - without associated achenes they are not diagnostic to species. They are of no known value for domestication studies. Well preserved achenes are the subject of morphometric analyses, but are less useful when they popped because their shape is then distorted to varying degrees. Achenes with receptacles (thickened portion of the stem to which the fruit adheres) and perianth base are another well-preserved form that can be analyzed in domestication studies. Corrections for comparing specimens with and without preserved receptacles are given in Table 2 . The perianth is the flower, which adheres to mature erect knotweed achenes but is almost always absent on carbonized achenes. The examples with most of their perianth preserved shown here are from my carbonization experiments; the rest of the pictured achenes are from archaeological assemblages. 


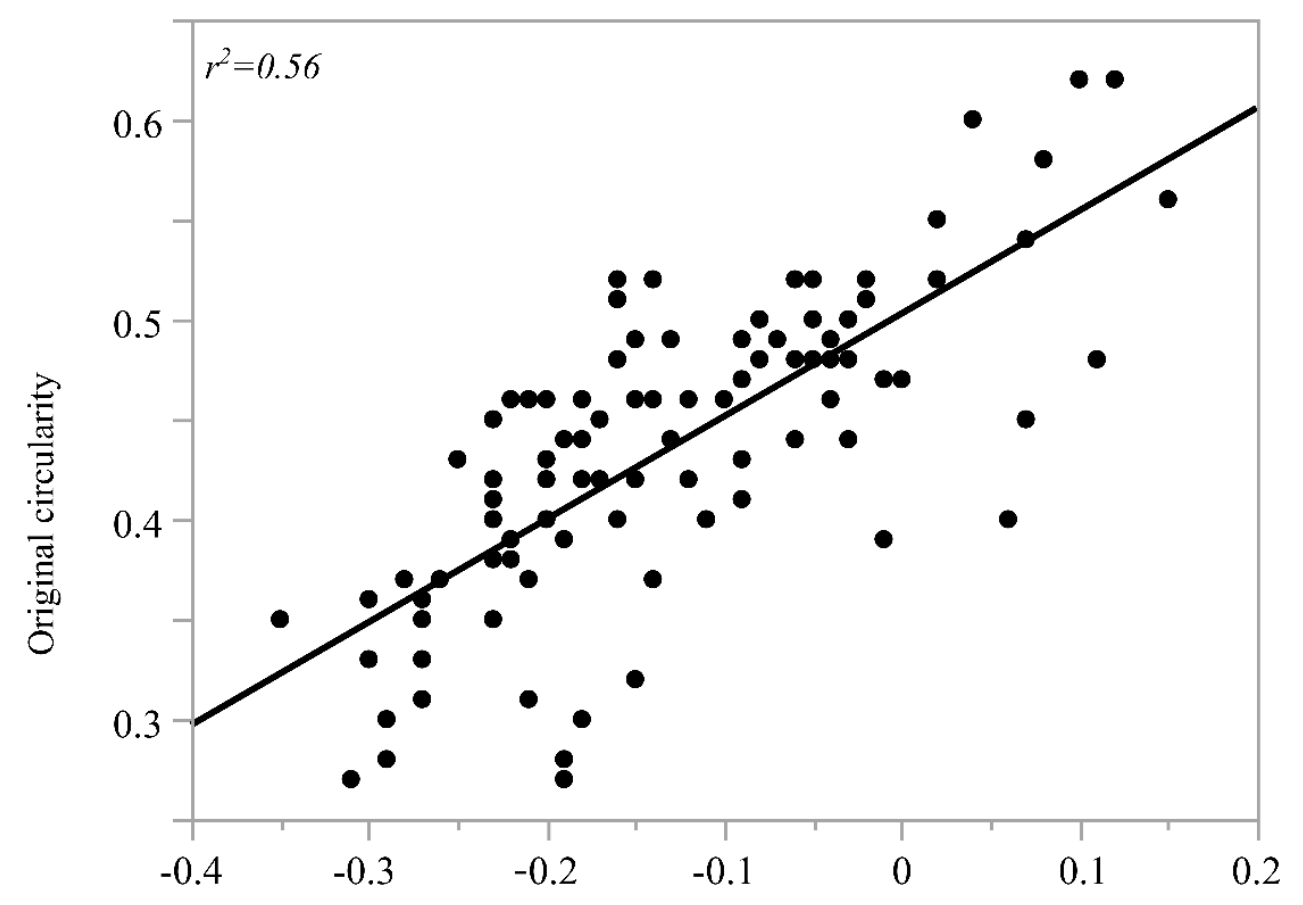

Change in circularity

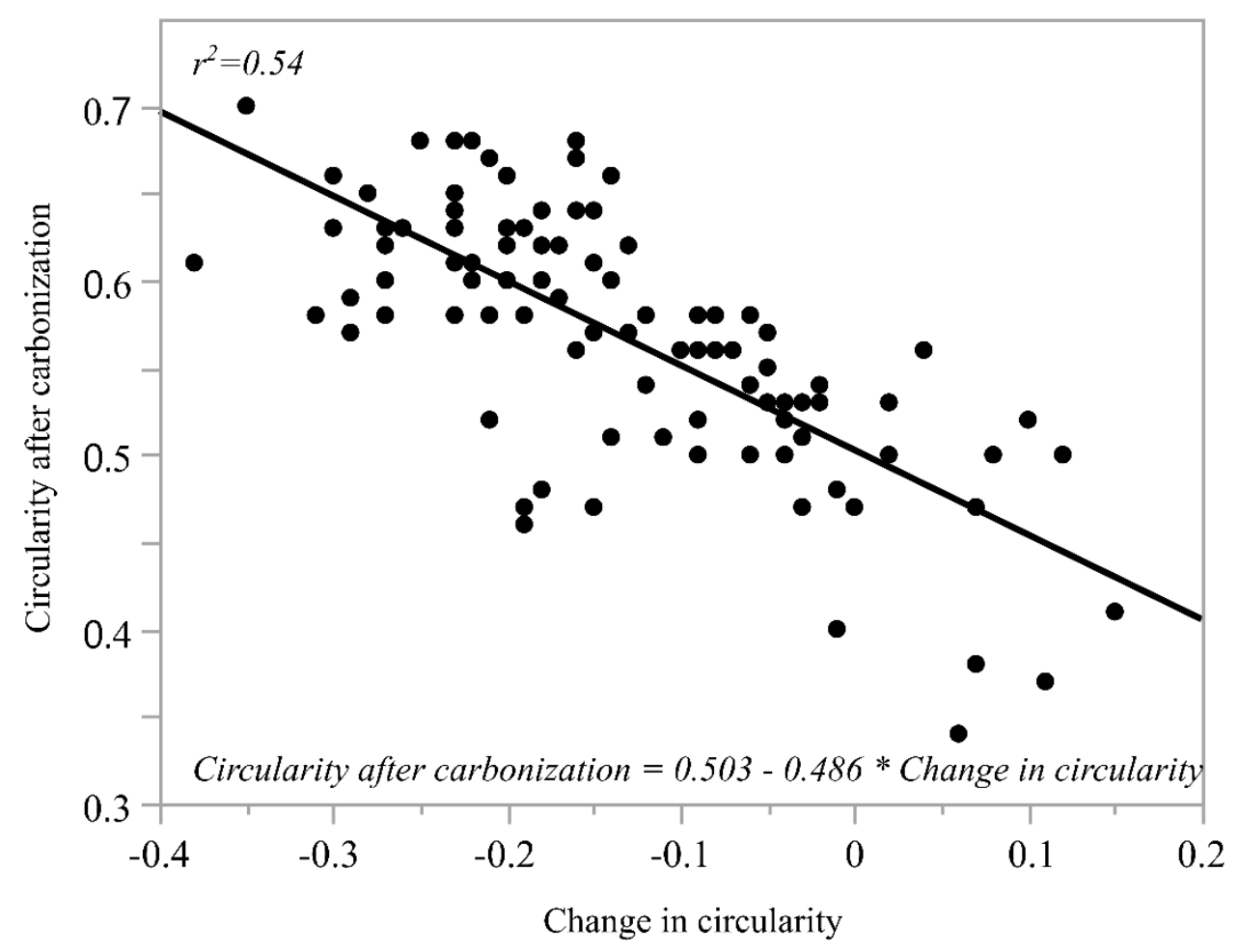

Figure 2: Shows the strong correlations between achene circularity and change in circularity. The equation of the line fit to the correlation between post-carbonization circularity and change in circularity was used to derive the correction factor recommended for achene shape (Table 2; Table 5). 


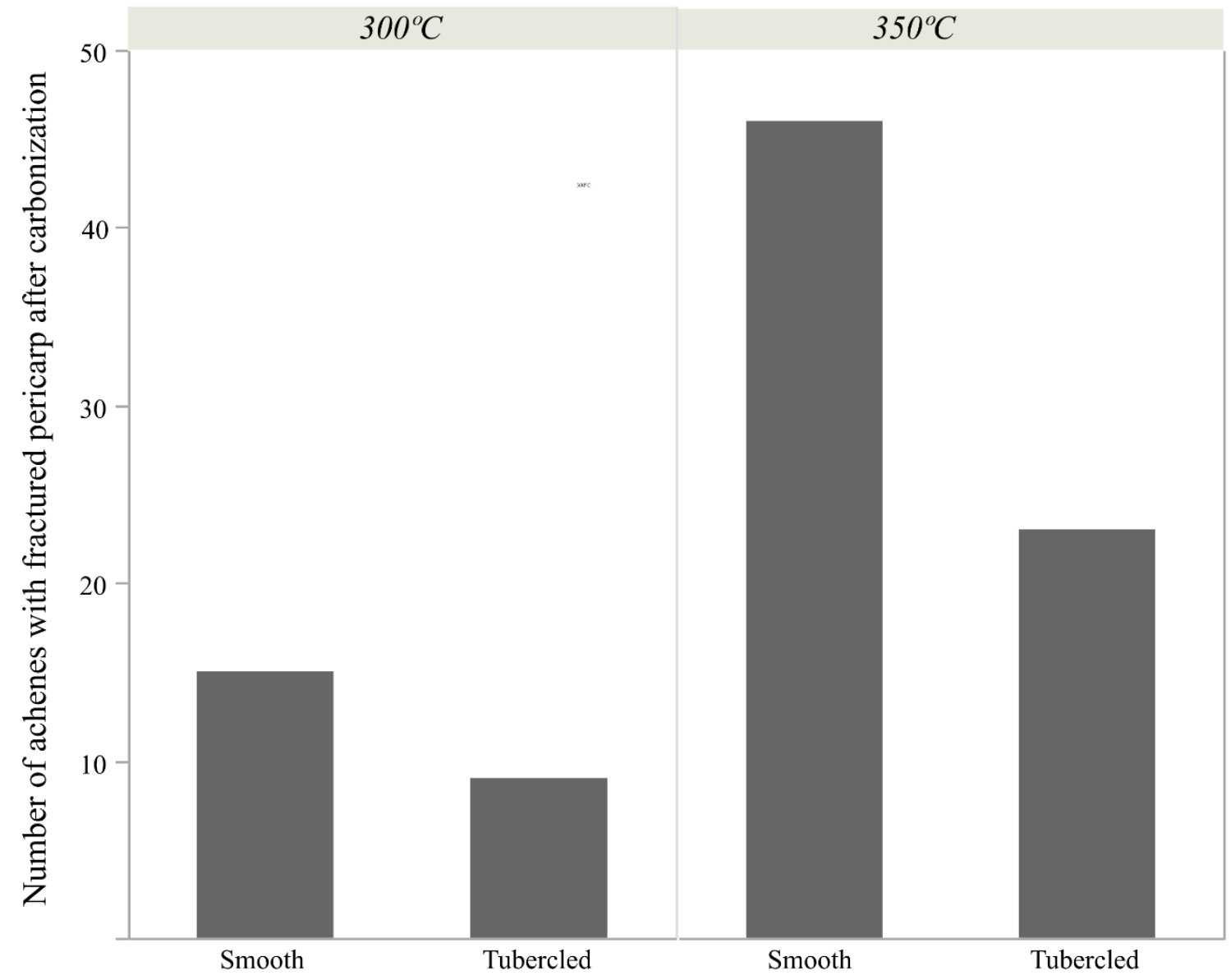

Figure 3: Shows the differential preservation of smooth and tubercled morphs after 30 minutes at $300^{\circ} \mathrm{C}$ and $350^{\circ} \mathrm{C}$, respectively.
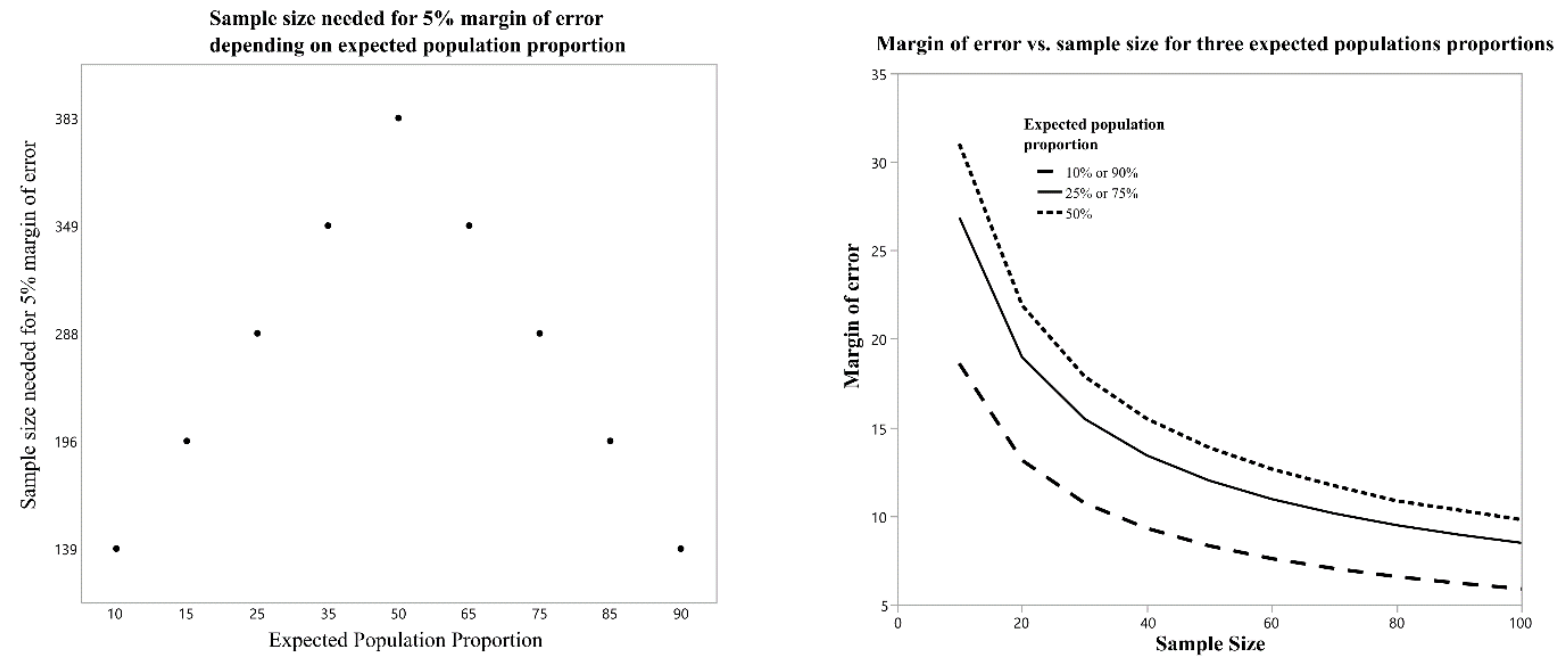
Figure 4. These two charts are visualizations of the probabilistic relationship between population proportion and sample size. For both graphs, confidence is set at 95\%. Left: It is more difficult to estimate population proportion accurately from a sample the closer the population proportion is to 50/50. If the true population proportion is skewed towards one or the other type (90\% or $10 \%$ in this chart), it is relatively easy to estimate. Right: Since the ideal sampling conditions cannot always be met, the graph on the right shows the margins of error for different sample sizes given different true population proportions (which are unknown for archaeological assemblages). The maximum population proportion of smooth morphs observed in modern wild populations is $72 \%$. Example: With a sample of 30, the margin of error for a population proportion of $75 \%$ is 15.49 . In other words, we cannot be confident that a sample $(n=30)$ with a proportion of $90 \%$ smooth morphs is outside of the range of natural variation. At $n=40$, these two hypothetic populations (75\% and $90 \%$ ) still have slightly overlapping expected sample proportion ranges: $61-89 \%$ and $81-99 \%$, respectively. However, if we have a sample of 40 with a proportion $>89 \%$ smooth morphs, we can be confident that it is outside the natural range of variation. There is some overlap in expected ranges even with large samples of $>100$, which makes it hard to draw definite conclusions about the domestication syndrome of archaeological samples, even large ones, with sample proportions in the high 70 s or low 80 s, like the Westpark assemblage (see text). 